\title{
ANÁLISE ECONÔMICA DE EMPRESAS PRESTADORAS DE SERVIÇO FLORESTAL EM DUAS REGIÕES DO ESTADO DE SANTA CATARINA
}

\author{
Dagoberto Stein de Quadros ${ }^{1}$, Jorge Roberto Malinovski ${ }^{2}$ \\ ${ }^{1}$ Eng. Florestal. Dr., Depto. de Engenharia Florestal, FURB, Blumenau, SC, Brasil - dagobert @ furb.br \\ ${ }^{2}$ Eng. Florestal. Dr., Depto. de Ciências Florestais, UFPR, Curitiba, PR, Brasil - malinovski@ufpr.br \\ Recebido para publicação: 15/03/2010 - Aceito para publicação: 08/09/2011
}

\begin{abstract}
Resumo
Este trabalho teve como objetivo caracterizar economicamente as prestadoras de serviço florestal a partir de análises de custo e de rentabilidade. $\mathrm{O}$ estudo foi realizado junto às prestadoras de serviço florestal que atuam nas regiões do Vale do Itajaí e Planalto Serrano do estado de Santa Catarina. Foram amostradas 46 empresas que executam atividades de silvicultura, colheita de madeira e transporte florestal. Foi caracterizada a composição dos custos, a proporção dos custos diretos e indiretos e dos custos fixos e variáveis no custo total. A partir das metodologias do Earning Before Interest, Taxes, Depreciation and Amortization (EBITDA), lucro de caixa (lucro antes da depreciação e do juro) e lucro econômico, analisou-se o ponto de equilíbrio, a rentabilidade sobre as vendas e sobre o capital. As empresas de silvicultura, colheita de madeira mecanizada e transporte florestal apresentaram ótimas rentabilidades sobre as vendas. As grandes prestadoras de serviço apresentaram melhores condições econômicas. As prestadoras de serviço possuem altos custos indiretos e alta participação de custos fixos nos custos totais. As empresas de colheita de madeira que atuam por meio de sistema manual e semimecanizado obtiveram resultados insatisfatórios em termos de ponto de equilíbrio. As rentabilidades encontradas foram semelhantes em ambas as regiões.

Palavras-chave: Prestadoras de serviço florestal; análise de custo; rentabilidade.
\end{abstract}

\begin{abstract}
Economic analysis of rendering companies of forest service in two regions of the state of Santa Catarina. This research aims at improve an economic description of forest service companies based on cost and profit analyses. The study focused companies present in 'Vale do Itajaí' and 'Planalto Serrano' regions, in the State of Santa Catarina. Forty six companies were sampled, they develop forestry services such as wood extraction, and forest transport. Their cost composition, amount of direct and indirect costs, as well as fixed and variable costs within the total cost were characterized. Based on the Earning Before Interest, Taxes, Depreciation and Amortization (EBITDA), cash earning (Earnings Before Depreciation and Interest), and economic earning methodologies, it was analyzed their break-even point, as well as profitability by sales and capital. The forestry, mechanized wood extracting, and forest transport companies presented high profitability on sales. The big service companies revealed better economic conditions. The service companies have high indirect costs and a high participation of fixed costs in total cost. Wood extracting companies that improve manual or semi-mechanized systems had unsatisfactory results in relation to the break-even point. The identified profitability is similar in both regions.

Keywords: Forest service renderers; cost Analysis; profitability.
\end{abstract}

\section{INTRODUÇÃO}

Grande parte dos serviços executados nas áreas de reflorestamento das empresas de base florestal no Brasil é realizada por empresas prestadoras de serviço florestal que, de certo modo, são uma das bases de sustentação dos segmentos industriais que utilizam a madeira reflorestada no seu processo produtivo.

A análise econômica dessas empresas tem despertado o interesse de inúmeros agentes do setor, pois os custos delas deveriam subsidiar a definição dos preços dos serviços florestais e estes deveriam ser condizentes com a necessidade de sustentabilidade econômica dessas empresas. Analisando a evolução do tema nos últimos anos, percebe-se que a definição dos preços na prestação de serviços florestais sempre 
foi destaque, no entanto, nota-se que os estudos relacionados, ao mesmo, concentram-se na avaliação dos custos das máquinas e implementos e na sua mão de obra, sendo quase inexistentes os casos que estudam as empresas prestadoras de serviço florestal de forma a abranger todos os seus custos.

Com relação à aplicação de modelos de custo para a análise de atividades florestais, tanto para a silvicultura como para a colheita de madeira e transporte florestal, pode-se afirmar que nos últimos anos essa área do conhecimento vem se desenvolvendo de forma evidente. A respeito do tema, Malinovski e Malinovski (1998) esclareceram que o principal fator limitante para a determinação dos custos nessas empresas é o volume anual colhido, pois maiores volumes podem justificar maiores investimentos quando aliados a contratos por bons períodos.

Valente et al. (2003) desenvolveram uma classificação dos custos voltada para a análise em serviços de transporte. De acordo com os autores, esses custos podem ser divididos em dois grandes grupos: primeiramente em diretos e indiretos, para depois, em uma classificação subsequente, em fixos e variáveis.

Malinovski (1983) caracterizou a metodologia do custo-hora para máquinas florestais proposto pela Organização das Nações Unidas para Agricultura e Alimentação/Economic Commission for Europe/Kuratorium für Waldarbeit und Forsttechnik (FAO/ECE/KWF). Essa metodologia subdividia os custos das máquinas em fixos (juros, seguros, impostos e garagem), semifixos (depreciação e concertos) e variáveis (combustíveis e lubrificantes), além do custo de pessoal e de empreitada (neste último incluíamse o lucro, o risco e os impostos).

Diaz e Mac Donagh (2001) em estudo realizado na região de Missiones/Argentina, analisaram quatro sistemas de colheita de pínus nas operações de corte, extração e carregamento, que variam de acordo com o seu nível de mecanização, volume individual das árvores e volume de trabalho de cada empresa. Para analisar os custos dessas operações, também se utilizaram da metodologia da FAO/ECE/KWF.

Birro et al. (2002), com o objetivo de fazer uma análise técnica e econômica de uma atividade de colheita de madeira, empregaram a metodologia de custo fixo e variável na determinação dos custos operacionais. Väätäinen et al. (2004), ao estudarem máquinas florestais na Finlândia, fizeram as análises de custo sobre as horas de funcionamento das mesmas. Os autores destacam que os custos dos impostos não foram calculados. Ducatti (2006) apresentou a composição dos preços das atividades de silvicultura, colheita de madeira (sistema semimecanizado e mecanizado) e transporte florestal.

Morais Filho (2006) analisou a capacidade técnica e econômica das empresas prestadoras de serviço florestal por meio da análise dos custos diretos e indiretos, tais como a remuneração do capital, a depreciação dos bens, os custos de treinamento e de Equipamentos de Proteção Individual (EPI). Esse trabalho enfatiza que é necessário computar alguns custos de menor expressão, que na maioria das vezes são deixados fora dos cálculos, como materiais de limpeza e despesas de escritório, dentre outros.

A conjuntura atual que envolve a temática, bem como os conhecimentos teóricos existentes, permite definir o seguinte problema de pesquisa: "Como caracterizar e analisar economicamente as empresas prestadoras de serviço em diferentes atividades florestais?".

O problema de pesquisa admitiu definir como objetivo principal a avaliação dos parâmetros de economicidade das empresas prestadoras de serviço em diferentes atividades florestais. Os objetivos específicos procuraram obter a determinação da composição dos custos das empresas, a análise dos custos diretos e indiretos, dos custos fixos e variáveis, dos custos desembolsáveis e não desembolsáveis, do lucro econômico, do lucro via caixa e do EBITDA e do ponto de equilíbrio. Além da definição desses parâmetros, o modelo de análise estruturado neste trabalho teve como meta definir a rentabilidade sobre as vendas e sobre o capital a partir das características operacionais de cada empresa prestadora de serviço florestal.

A caracterização econômica das empresas prestadoras de serviço florestal permite distinguir e conhecer as empresas que atuam em distintas atividades florestais. Essa é a hipótese principal do presente estudo.

\section{MATERIAIS E MÉTODOS}

\section{Material}

O estudo foi realizado em duas regiões do estado de Santa Catarina:

\section{Região I - Vale do Itajaí/SC}

Composta pelos municípios de Apiúna, Ascurra, Blumenau, Gaspar, Ibirama, Indaial e Timbó, essa região possui economia baseada na indústria têxtil e de alimentos, havendo poucas empresas de base florestal, de modo que a atividade florestal não é a principal atividade da economia regional. Nessa região, o relevo que predomina é o montanhoso, com alta incidência de ravinas, e a vegetação original 
constitui-se da Floresta Ombrófila Densa. Existe na região reflorestamentos dos gêneros eucalipto e pínus, com predominância do gênero eucalipto.

\section{Região II - Planalto Serrano/SC}

Composta pelos municípios de Correia Pinto, Lages, Otacílio Costa, Palmeira, Ponte Alta, Ponte Alta do Norte, Santa Cecília e São Cristóvão do Sul, essa região possui economia baseada na indústria de base florestal, existindo diversas empresas produtoras de papel e celulose, painéis, além de serrarias. Salienta-se que a atividade de reflorestamento é a sustentação da economia regional e os reflorestamentos do gênero pínus predominam. O relevo dominante é suave ondulado e a vegetação original constitui-se da Floresta Ombrófila Mista.

Justifica-se a escolha dessas duas regiões por serem distintas e representarem a atividade de reflorestamento no estado de Santa Catarina. A primeira região, Vale do Itajaí/SC, representa as regiões em que o reflorestamento não é a principal atividade econômica regional. A segunda, Planalto Serrano/SC, representa a região em que o reflorestamento, de certa forma, confere sustentação econômica à região.

A base amostral constituiu-se de um cadastro das empresas prestadoras de serviço florestal que atuam nas duas regiões do estudo. Esse cadastro foi realizado a partir das empresas que se utilizam de prestadores de serviço para executar as atividades de silvicultura, colheita de madeira e transporte florestal em suas áreas de reflorestamento. Foram cadastradas 142 empresas prestadoras de serviço, das quais 84 não mostraram interesse em participar desta pesquisa. Das 58 empresas prestadoras de serviço restantes, eliminaram-se 12, pois os dados fornecidos por elas foram inconsistentes. Dessa forma, foram analisadas 46 empresas prestadoras de serviço florestal, que constituíram a amostra do presente estudo, perfazendo um percentual de, aproximadamente, $29,00 \%$ da amostra. A tabela 1 apresenta esses dados por região.

Tabela 1. Empresas prestadoras de serviço cadastradas, pré-analisadas e pesquisadas.

Table 1. Registered service companies previously analyzed and researched.

\begin{tabular}{lccc}
\hline Localização & Cadastradas & Pré-analisadas & Amostradas \\
\hline Região I & 81 & 32 & 24 \\
Região II & 61 & 26 & 22 \\
Total & 142 & 58 & 46 \\
\hline
\end{tabular}

Estratificou-se a amostra a partir das atividades de silvicultura, colheita de madeira e transporte florestal. Essas atividades foram assim caracterizadas:

- Silvicultura: empresas que atuam em implantação de reflorestamento, especificamente nas operações de preparo do terreno, plantio e tratos culturais e silviculturais; não se incluíram aqui as empresas de produção de mudas florestais;

- Colheita de Madeira: empresas que executam atividades de desbaste e/ou corte raso de reflorestamentos;

- Transporte Florestal: empresas que realizam o transporte de madeira na forma de toretes e toras originadas de reflorestamentos.

As empresas prestadoras de serviço também foram classificadas pelo seu grau de mecanização, a partir dos seguintes critérios:

- Manual: empresas que se utilizam de serviços manuais, além de máquinas e implementos portáteis;

- Semimecanizado: empresas que utilizam máquinas e implementos portáteis e tratores agrícolas adaptados ou não à atividade florestal;

- Mecanizado: empresas que atuam apenas a partir da utilização de tratores agrícolas e/ou florestais (Tabela 2).

Tabela 2. Empresas prestadoras de serviço amostradas por atividade e grau de mecanização.

Table 2. Service companies sampled by activity and mechanization degree.

\begin{tabular}{lcccc}
\hline Atividade & Manual & Semimecanizado & Mecanizado & Total \\
\hline Silvicultura & 0 & 10 & 0 & 10 \\
Colheita de Madeira & 8 & 14 & 4 & 26 \\
Transporte Florestal & 0 & 0 & 10 & 10 \\
Total & 8 & 24 & 14 & 46 \\
\hline
\end{tabular}




\section{Método}

A metodologia utilizada neste trabalho constituiu-se da estruturação do sistema de cálculo de custo e de rentabilidade da empresa. A análise de custo foi realizada inicialmente a partir da classificação de todos os custos em diretos e indiretos, para, posteriormente, analisar os mesmos custos de acordo com a classificação dos custos em fixos e variáveis.

Análise dos custos diretos e indiretos

Neste trabalho, foram considerados como custos diretos os seguintes custos de produção:

- máquinas e implementos, constituídos de custos de capital, depreciação, reparos e manutenção, combustível, lubrificantes, taxas, seguros e multas;

- mão de obra de produção, constituídos de salários, encargos e benefícios sociais, alimentação, EPI e Equipamento de Proteção Coletiva (EPC).

- Como custos indiretos foram considerados os custos relacionados à administração:

- máquinas e implementos, constituídos de custos de capital, depreciação, reparos e manutenção, combustível, lubrificantes, taxas, seguros e multas;

- mão de obra de administração, constituídos de salários, encargos e benefícios sociais, alimentação, EPI e EPC;

- despesas administrativas, incluindo-se os serviços contábeis, advocatícios, de engenharia, bancários, telefone fixo e móvel, energia, alvará e aluguéis de escritório, entre outros;

- despesas governamentais, compostos pelos impostos sobre a venda, marketing, comissão de venda e provisão para devedores duvidosos.

A partir da Associação Brasileira de Normas Técnicas (ABNT, 2006), que trata da avaliação de máquinas, equipamentos, instalações e bens industriais em geral, definiu-se a denominação de "máquinas e implementos" para designar todos os itens relacionados às ferramentas, motosserras, tratores agrícolas, tratores florestais, veículos, caminhões e ônibus, entre outros bens, tanto diretos como indiretos, das empresas prestadoras de serviço florestal.

Para calcular os custos das máquinas e implementos diretos e indiretos, foram definidas a especificação das máquinas e implementos quanto à quantidade, ao modelo e ao ano de fabricação. Determinaram-se as horas trabalhadas das máquinas e implementos, o rendimento, o valor de aquisição, o valor residual e a vida útil. Em seguida, foram feitos os cálculos dos custos das máquinas e implementos.

Neste trabalho, o custo de oportunidade foi calculado a partir da taxa de juros da caderneta de poupança, que é calculada a partir da taxa de juro de $0,50 \%$ ao mês mais a variação da Taxa Referencial (TR), conforme estabelecido pela Caixa Econômica Federal (CEF, 2007). Como se observa na economia nacional, na maioria das vezes essa taxa tem uma variação abaixo da maioria dos índices de inflação. Por esse motivo, procedeu-se ao cálculo da taxa de juros real. Para tanto, se considerou como deflator a média de quatro outros índices de inflação: Índice Nacional de Preços ao Consumidor (INPC), Índice Nacional de Preços ao Consumidor Amplo (IPCA), Índice Geral de Preços - Mercado (IGM-M) e Índice de Preços ao Consumidor da Fundação Instituto de Pesquisas Econômicas (IPC-FIPE). Assim, definiu-se uma taxa de juros real de 4,19\% ao ano. Essa análise foi realizada a partir da variação dos índices desde o ano de 1995 (pós Plano Real) até o ano de 2007.

Martins (2003) define a seguinte fórmula para determinar o custo de oportunidade do capital:

$$
C O=V A \cdot i
$$

em que: $C O=$ custo de oportunidade ( $\mathrm{R} \$ /$ mês);

$V A=$ valor presente do bem $(\mathrm{R} \$)$;

$i=$ taxa de juros (\% ao mês).

Neste trabalho, utilizou-se a depreciação linear apresentada por Hirschfeld (2000), que define a seguinte fórmula para o cálculo da depreciação:

$$
D=\frac{V a-V r}{n}
$$

em que: $D=$ depreciação (R $\$$ mês);

$V a=$ valor atual $(\mathrm{R} \$)$;

$V r=$ valor residual $(\mathrm{R} \$)$;

$n=$ vida útil (mês). 
Utilizou-se a metodologia da depreciação linear pelo de fato de ela permitir o cálculo do custo da depreciação a partir do valor real dos bens na data da análise.

Nessa análise, optou-se por calcular os reparos e manutenção a partir da fórmula de Malinovski (1999):

$$
C R M=V . C f C
$$

em que: $C R M=$ custo de Reparos e Manutenção (R\$/mês);

$V=$ valor de aquisição $(\mathrm{R} \$)$;

$C f C=$ coeficiente de conserto $(\%)$.

Nos casos em que a empresa possuía os valores históricos médios gastos com os reparos e manutenção, utilizaram-se esses valores na análise.

No presente trabalho, foi utilizada a fórmula apresentada por Malinovski (1999):

$$
C=C h \cdot V \cdot Q h
$$

em que: $C=$ custo de combustível (R $\$ /$ mês);

Ch $=$ consumo/hora $(\mathrm{L} / \mathrm{h})$;

$V=$ valor do litro de combustível (R $\$ / \mathrm{L})$;

$Q h=$ quantidade de horas/mês (h/mês).

Nos casos em que a empresa possuía os valores históricos médios gastos com o combustível, utilizaram-se esses valores na análise.

Os custos de lubrificantes foram calculados a partir da fórmula apresentada por Malinovski (1999):

$$
L=C \cdot 0,20
$$

em que: $L=$ custo de lubrificantes (R $\$ / \mathrm{mês})$;

$C=$ custo de combustível ( $\mathrm{R} \$ / \mathrm{mês})$;

0,20 = índice de lubrificante em relação ao consumo de combustível.

Nos casos em que a empresa possuía os valores históricos médios desembolsados com os lubrificantes, utilizaram-se esses valores na análise.

Utilizou-se a fórmula apresentada por Hildebrand (1995) para cálculo dos custos das taxas, seguros e multas:

$$
C T x / S / M=(T x+S+M) / 12
$$

em que: $C T x / S / M=$ custo de taxas, seguros e multas ( $\mathrm{R} \$ / \mathrm{mês})$;

$T x=$ taxas e licenciamento anual $(\mathrm{R} \$ / \mathrm{ano})$;

$S=$ seguros $(\mathrm{R} \$ / \mathrm{ano})$;

$M=$ multas (R $\$ /$ ano). históricos.

Esses custos também foram determinados pelo dirigente da empresa e foram baseados em dados

A definição dos custos de mão de obra de produção (direta) e administração (indireta) foi realizada em cada etapa da produção e para cada funcionário da administração. Em primeiro lugar, foram identificados os cargos existentes na prestadora de serviço, o número de funcionários e o salário mensal de cada funcionário. A partir da definição dos salários, definiram-se os encargos sociais (valores gastos sobre o salário que é exigido por lei) e os benefícios sociais (valores gastos sobre os salários que não são exigências legais). Neste trabalho foram considerados os encargos sociais definidos por Theiss e Krieck (2005), em um percentual de $85,47 \%$ sobre o salário básico.

Em cada um dos cálculos de custo de mão de obra, foram considerados os custos de benefícios sociais definidos pelo dirigente da prestadora de serviço. A fórmula abaixo foi utilizada para o cálculo do custo de mão de obra por trabalhador:

$$
C M O=N f . S . E S . B S
$$

em que: $C M O=$ custo de mão de obra (R\$/mês);

$N f$ = número de funcionários (unidade);

$S=$ salário mensal (R $\$ /$ mês);

$E S=$ percentual de encargos sociais (\%);

$B S=$ percentual de benefícios sociais $(\%)$. 
Após esses cálculos, definiram-se os valores mensais de custo de alimentação e de EPI. Os valores básicos do cálculo, utilizados na fórmula acima, foram apresentados pelos dirigentes das empresas.

As despesas administrativas foram determinadas a partir das informações fornecidas pelo dirigente da prestadora de serviço, baseadas no histórico de gastos mensais da empresa. Fizeram parte dessas despesas os desembolsos com serviços de contabilidade, engenharia e advocatícios, energia elétrica, água, telefone fixo e móvel, alvará, anuidade do Conselho Regional de Engenharia, Arquitetura e Agronomia (CREA), Imposto Predial e Territorial Urbano, anuidade do Sindicato Patronal, assinatura de revistas especializadas e outras despesas.

As despesas governamentais foram calculadas a partir dos impostos que incidem sobre a receita bruta mensal. Esses impostos são:

- Imposto sobre Renda da Pessoa Jurídica - IRPJ;

- Contribuição Social sobre o Lucro Líquido - CSLL;

- Contribuição para o Financiamento da Seguridade Social - COFINS;

- Programa de Integração Social/Programa de Formação do Patrimônio do Servidor Público PIS/PASEP;

- Imposto sobre Serviços de Qualquer Natureza - ISSQN.

Os percentuais de impostos sobre a receita bruta total variam de acordo com o percentual da receita bruta em 12 meses. A receita bruta mensal foi definida a partir da média histórica dos últimos seis meses. Também foram definidas pelo dirigente da prestadora de serviço outras despesas, tais como marketing, comissão de venda e provisão para devedores duvidosos (PDD) e índice de inadimplência, que é calculado a partir dos valores não recebidos em comparação com a receita total da empresa.

\section{Análise da lucratividade}

Calculou-se a lucratividade da empresa a partir de três metodologias: EBITDA, de caixa e econômica. Para calcular o lucro através do método do EBITDA, utilizou-se a fórmula apresentada por Vasconcelos (2002):

$$
\text { EBITDA }=(R-C T O)
$$

em que: $E B I T D A=$ lucro antes dos juros, impostos, depreciações e amortizações (R $\$ / m e ̂ s) ;$

$R=$ receita $(\mathrm{R} \$ / \mathrm{mês})$;

$C T o=$ custo total operacional menos os juros, impostos, depreciações e amortizações (R $\$ /$ mês).

Para calcular o lucro a partir do caixa, retiraram-se, do custo total, os custos não desembolsáveis. Portanto, foram excluídos os custos de capital e de depreciação dos custos de máquinas e implementos diretos e indiretos. Para calcular o lucro a partir do caixa utilizou-se a seguinte fórmula:

$$
L_{\text {caixa }}=\left(R-C T_{\text {caixa }}\right)
$$

em que: $L$ caixa = lucro do caixa (R $\$ /$ mês);

$R=$ receita $(\mathrm{R} \$ / \mathrm{mês})$;

CT caixa $=$ custo total menos o custo de capital e depreciações (R\$/mês).

O lucro econômico foi calculado a partir do custo total da empresa, assim definido por Pindyck e Rubinfeld (1994):

$$
L_{\text {econômico }}=\left(R-C T_{\text {econômico }}\right)
$$

em que: $\mathrm{L}$ econômico = lucro econômico (R $\$ / \mathrm{mês})$;

$R=$ receita $(\mathrm{R} \$ / \mathrm{mês})$;

$\mathrm{CT}$ econômico $=$ custo total (inclui custo de capital e depreciações $(\mathrm{R} \$ / \mathrm{mês})$ ).

\section{Análise dos custos fixos e variáveis}

A conceituação de custos fixos e variáveis permitiu classificar os custos das empresas prestadoras de serviço florestal a partir desses conceitos. Neste trabalho, foram considerados como custos fixos:

- custo de oportunidade das máquinas e implementos; 
- depreciação das máquinas e implementos;

- mão de obra de produção e administração (salários, encargos sociais e sociais, alimentação e EPI);

- despesas administrativas.

- Como custos variáveis, foram considerados:

- reparos e manutenção, combustível, lubrificantes e multas das máquinas e implementos;

- despesas governamentais e outras.

\section{Análise do ponto de equilíbrio}

Para a obtenção do ponto de equilíbrio, utilizou-se a fórmula descrita por Martins (2003):

$$
P E=\frac{C F}{(P V-C V u n)} \cdot 100
$$

em que: $\mathrm{PE}=$ ponto de equilíbrio $(\%)$;

$\mathrm{CF}=$ custo fixo $(\mathrm{R} \$ / \mathrm{mês})$

$\mathrm{PV}=$ preço de venda $(\mathrm{R} \$$ /unidade $)$;

$\mathrm{CVun}=$ custo variável unitário $(\mathrm{R} \$$ /unidade $)$.

A análise do ponto de equilíbrio foi realizada a partir de três metodologias de determinação de lucro apresentadas neste estudo, quais sejam: EBITDA, de caixa e econômico.

\section{Análise de rentabilidade}

A partir dos cálculos dos custos anteriormente caracterizados, foram calculados os valores de rentabilidade sobre as vendas e sobre o capital fixo.

Calculou-se a rentabilidade sobre as vendas a partir da fórmula proposta por Ross et al. (1995):

$$
R_{\text {vendas }}=\frac{l l}{R O T} \cdot 100
$$

em que: $\mathrm{R}$ vendas = rentabilidade sobre as vendas $(\%)$;

11 = lucro líquido $(\mathrm{R} \$ / \mathrm{mês})$;

$\mathrm{ROT}=$ receita operacional total (R $\$ /$ mês).

Neste trabalho, fez-se a análise da rentabilidade sobre as vendas a partir da fórmula acima, no entanto, substituiu-se o lucro líquido obtido pelo EBITDA pelo lucro obtido por meio do caixa e pelo lucro econômico. (1995):

A rentabilidade sobre o capital foi calculada a partir da fórmula apresentada por Ross et al.

$$
R_{\text {patrimônio }}=\frac{l l}{P L} \cdot 100
$$

em que: $\mathrm{R}$ patrimônio = rentabilidade sobre o patrimônio $(\%)$;

11 = lucro líquido $(\mathrm{R} \$ / \mathrm{ano})$

$\mathrm{PL}=$ patrimônio líquido $(\mathrm{R} \$)$.

Com essa fórmula, fez-se a análise da rentabilidade sobre o capital, a partir do lucro líquido calculado pelo método EBITDA, de caixa e lucro econômico.

\section{Planilha de custo e rentabilidade}

A partir dos cálculos de custos elencados anteriormente, estruturou-se para cada caso estudado uma planilha de custos no MICROSOFT OFFICE EXCEL_ß. Essa planilha tomou como base a caracterização dos custos em diretos e indiretos mensais (os custos diretos também foram calculados por unidade). Em seguida, definiram-se os mesmos custos pelo critério de custo fixo e variável. Após todos os custos terem sido calculados pela classificação de direto e indireto, assim como fixo e variável, elaborouse uma planilha-resumo, na qual ainda se caracterizam os custos como desembolsáveis e não desembolsáveis (nestes, excluem-se os custos de oportunidade e de depreciação). Após os cálculos de custo, procedeu-se ao cálculo das rentabilidades sobre as vendas e sobre o capital, a partir dos três conceitos de lucratividade (EBITDA, de caixa e econômica). 


\section{Critérios de homogeneização dos dados}

Com o objetivo de analisar os custos das empresas prestadoras de serviço, o custo total foi igualado a $100 \%$. A partir desse valor relativo, foram calculados os percentuais de participação de cada sub-grupo de custos (máquinas e implementos diretos e indiretos, mão de obra direta e indireta, despesas administrativas e despesas governamentais). $\mathrm{Na}$ análise dos custos diretos e indiretos, bem como dos custos fixos e variáveis, procedeu-se da mesma maneira, ou seja, igualou-se o custo total ao valor relativo (100\%) e comparou-se cada tipo de custo com esse custo total relativo, obtendo-se assim o percentual de cada custo.

Os valores de ponto de equilíbrio, de rentabilidade sobre as vendas e sobre o capital, foram analisados diretamente a partir dos valores calculados, pois estes já se encontram em valores percentuais, ou seja, já estão relativizados à produção total, à receita bruta ou ao capital, respectivamente.

\section{RESULTADOS E DISCUSSÃO}

\section{Composição dos custos}

Na tabela 3 apresenta-se a composição dos subgrupos de custo. As empresas de silvicultura possuem uma proporção de custos de mão de obra direta de $44 \%$, o que demonstra a alta utilização de mão de obra nesse tipo de atividade. A participação dos custos de máquinas e implementos indiretos nessas mesmas empresas é de $8 \%$, e de mão de obra indireta de $11 \%$, constatação que decorre da necessidade de apoio logístico para o pessoal de produção.

Tabela 3. Composição do custo total por subgrupo de custo.

Table 3. Composition of total cost by cost sub-group.

\begin{tabular}{|c|c|c|c|c|c|c|c|}
\hline Atividade & $\begin{array}{c}\text { Grau de } \\
\text { mecanização }\end{array}$ & $\begin{array}{c}\text { Máquinas e } \\
\text { implementos } \\
\text { diretos } \\
(\%)\end{array}$ & $\begin{array}{c}\text { Mão de } \\
\text { obra } \\
\text { direta } \\
(\%) \\
\end{array}$ & $\begin{array}{c}\text { Máquinas e } \\
\text { implementos } \\
\text { indiretos } \\
(\%) \\
\end{array}$ & $\begin{array}{c}\text { Mão de } \\
\text { obra } \\
\text { indireta } \\
(\%) \\
\end{array}$ & $\begin{array}{c}\text { Despesas } \\
\text { administrativas } \\
(\%)\end{array}$ & $\begin{array}{c}\text { Despesas } \\
\text { governamentais } \\
(\%)\end{array}$ \\
\hline Silvicultura & Semimecanizado & 19 & 44 & 8 & 11 & 2 & 16 \\
\hline \multirow{3}{*}{$\begin{array}{l}\text { Colheita de } \\
\text { madeira }\end{array}$} & Manual & 7 & 60 & 7 & 14 & 3 & 9 \\
\hline & Semimecanizado & 27 & 46 & 3 & 10 & 2 & 12 \\
\hline & Mecanizado & 43 & 20 & 4 & 12 & 1 & 20 \\
\hline $\begin{array}{l}\text { Transporte } \\
\text { florestal }\end{array}$ & Mecanizado & 49 & 25 & 3 & 7 & 2 & 14 \\
\hline
\end{tabular}

Nas empresas de colheita de madeira com sistemas manuais, os custos de máquinas e implementos diretos são baixos (7\%), enquanto que nas empresas que atuam com sistemas de colheita de madeira mecanizados chega a 43\%, destacando-se a grande diferença existente entre esses tipos de sistemas. Em sentido contrário, apresentam-se os percentuais de custos de mão de obra direta, com $60 \%$ para o sistema de colheita manual e $20 \%$ para sistemas mecanizados. Associado a essa constatação está o fato de que as empresas que operam com sistemas manuais estão em sua grande maioria localizadas na região do Vale do Itajaí/SC, e as empresas que operam com sistemas mecanizados estão todas na região do Planalto Serrano/SC.

Destaca-se ainda a baixa escolaridade dos dirigentes das empresas que operam na colheita de madeira manual. Esse índice melhora à medida que o grau de mecanização passa para sistemas semimecanizados e mecanizados. Em muitos casos, o proprietário da empresa que opera em sistemas manuais também atua no processo produtivo, como operador de máquinas e implementos, o que não ocorre nos outros dois graus de mecanização dessa atividade.

Há um aumento da participação dos custos governamentais quando se altera de um sistema manual para semimecanizado e mecanizado. Esse aumento está associado ao aumento do volume de produção, que resulta em uma receita bruta maior, com maiores alíquotas de impostos a serem pagos.

As empresas prestadoras de serviço de transporte florestal possuem alta proporção de custos de máquinas e implementos diretos, pois estes representam $49 \%$ do custo total. Os $25 \%$ de participação do custo de mão de obra direta no custo total podem ser considerados altos nesse tipo de empresa, pois esta é a atividade que possui o menor número de funcionários por empresa, porém com os salários mais altos. 
As empresas de transporte florestal que constituíram a amostra são as que possuem a menor proporção de custos de máquinas e implementos e mão de obra indiretos, o que demonstra a menor necessidade de apoio administrativo.

\section{Custos diretos e indiretos}

$\mathrm{Na}$ tabela 4, observa-se que as empresas prestadoras de serviço de silvicultura, bem como de colheita de madeira mecanizada, possuem as maiores proporções de custos indiretos, com $37 \%$ do custo total. Isso pode ser explicado pela alta participação dos custos de mão de obra indireta e máquinas e implementos indiretos nos custos totais das empresas, pois elas possuem alta necessidade administrativa e de apoio logístico.

Tabela 4. Custo direto e indireto.

Table 4. Direct and indirect cost.

\begin{tabular}{lccc}
\hline Atividade & Grau de mecanização & Custo direto total (\%) & Custo indireto total (\%) \\
\hline Silvicultura & Semimecanizado & 63 & 37 \\
\hline \multirow{3}{*}{ Colheita de madeira } & Manual & 67 & 33 \\
& Semimecanizado & 73 & 27 \\
& Mecanizado & 63 & 37 \\
\hline Transporte florestal & Mecanizado & 74 & 26 \\
\hline
\end{tabular}

Nota-se que as empresas prestadoras de serviço de transporte florestal apresentaram o menor resultado em termos de análise de custo direto e indireto, pois os custos indiretos representaram $26 \%$ do custo total, o que demonstra a menor necessidade de custo de administração em relação ao custo total.

\section{Custos fixos e variáveis}

Partindo-se da análise da teoria do ponto de equilíbrio, para um mesmo nível de receita, quanto maior for a proporção de custos fixos em relação ao custo total, pior é a situação de equilíbrio de uma empresa, pois mais propensa a resultados negativos ela estará quando o volume de produção baixar. Observa-se na tabela 5 a situação de cada um dos cinco grupos analisados.

Tabela 5. Composição de custos fixos e variáveis.

Table 5. Composition of fixed and variable costs.

\begin{tabular}{lccc}
\hline Atividade & Grau de mecanização & Custo fixo total (\%) & Custo variável total (\%) \\
\hline Silvicultura & Semimecanizado & 65 & 35 \\
\hline \multirow{3}{*}{ Colheita de madeira } & Manual & 80 & 20 \\
& Semimecanizado & 63 & 37 \\
& Mecanizado & 52 & 48 \\
\hline Transporte florestal & Mecanizado & 48 & 52 \\
\hline
\end{tabular}

Nas empresas de silvicultura, que atuam em sistemas semimecanizados, $65 \%$ de seus custos são fixos, valor semelhante aos encontrados nas empresas de colheita semimecanizada (63\%). Isso ocorre devido a existir nessas empresas elevados custos de mão de obra direta, bem como altos custos de máquinas e equipamentos diretos e indiretos.

Nas empresas prestadoras de serviço de colheita de madeira, à medida que as atividades são mais mecanizadas diminui a proporção de custo fixo em relação ao custo total, pois, apesar de haver um aumento dos custos de oportunidade e de depreciação das máquinas e equipamentos, que são fixos, há um aumento em maior proporção dos demais custos de máquinas e equipamentos que são variáveis, como combustíveis, reparos e manutenção, assim como um aumento das despesas governamentais. Colabora com essa constatação o fato de haver uma diminuição do custo de mão de obra direta, que é fixo, à medida que a atividade é mais mecanizada.

As empresas de transporte florestal tiveram as menores proporções de custos fixos em relação aos variáveis, fato que ocorre devido ao alto índice de utilização de máquinas e implementos e aos elevados valores de despesas governamentais. 
Há uma acentuada diminuição na participação dos custos fixos em relação ao custo total à medida que aumenta o tamanho das empresas, pois os custos fixos são mais elevados nas microempresas, devido à elevada participação dos custos de mão de obra direta.

\section{Ponto de equilíbrio}

A tabela 6 permite observar que as empresas de silvicultura apresentaram necessidades de produção baixas $(71 \%)$ para atingirem o ponto de equilíbrio econômico, mesmo tendo uma proporção de custo fixo de $65 \%$, o que deriva de boas receitas obtidas por elas, que proporcionam uma boa condição de ponto de equilíbrio.

Tabela 6. Ponto de equilíbrio (EBITDA, de caixa e econômico).

Table 6. The break-even point (EBITDA, cash and economic).

\begin{tabular}{lcccc}
\hline Atividade & Grau de mecanização & EBITDA (\%) & Caixa (\%) & Econômico (\%) \\
\hline Silvicultura & Semimecanizado & 53 & 62 & 71 \\
\hline \multirow{3}{*}{ Colheita de madeira } & Manual & 84 & 93 & 97 \\
& Semimecanizado & 89 & 107 & 117 \\
& Mecanizado & 36 & 46 & 74 \\
\hline Transporte florestal & Mecanizado & 47 & 54 & 72 \\
\hline
\end{tabular}

As empresas de colheita de madeira que operam em sistemas semimecanizados possuem as piores condições de ponto de equilíbrio entre as cinco atividades analisadas, pois necessitam operar acima da sua capacidade instalada para obter as condições para atingir o equilíbrio. Essa constatação é verificada na análise de caixa e econômica. Já na análise do EBITDA ocorre uma melhor condição de equilíbrio. Essa constatação pode caracterizar que essas empresas atuam sob essa condição, ou seja, empresas que atuam sob essa condição não consideram nos seus custos o custo de capital, depreciação, amortização e impostos. A complexidade em se administrar essas empresas devido ao elevado envolvimento de mão de obra e máquinas e implementos diretos contribui com essa afirmação. Nessas empresas a maioria dos dirigentes possui baixo nível de escolaridade, o que dificulta ainda mais a administração econômica.

Em ótima situação encontram-se as empresas prestadoras de serviço de colheita de madeira mecanizada, que apresentaram as melhores condições de ponto de equilíbrio, pois este ocorre, na análise econômica, com 74\% do volume de produção, fato que decorre dos baixos custos fixos dessas empresas. Já as empresas de transporte florestal possuem condições econômicas satisfatórias. Os valores altos de receitas e os baixos custos fixos (48\%) proporcionam essa condição, com a qual também colaboram a administração e o apoio logístico de baixo custo. Nessas empresas também se encontram dirigentes com bons níveis de escolaridade.

A diferença entre o ponto de equilíbrio calculado pelo método do EBITDA, de caixa e econômico é maior nas empresas com maior grau de mecanização, devido à alta participação dos custos de máquinas e implementos, que carregam os custos de depreciação e de oportunidade, que são fixos e altos nessas empresas, assim como, também, porque é maior a participação dos custos governamentais.

\section{Rentabilidade sobre as vendas}

A rentabilidade sobre as vendas (Tabela 7), quando calculada a partir do lucro obtido por meio da metodologia do EBITDA, é maior que a calculada sobre o método de caixa, que, por sua vez é maior que a calculada por meio do método econômico. Essa constatação deriva da forma como o lucro é calculado em cada uma dessas metodologias, sendo a metodologia de cálculo de lucro econômico a mais correta e a que sempre deveria ser seguida quando se analisa empresas prestadoras de serviço florestal.

Ao se analisar a rentabilidade pelo método EBITDA, nota-se que as empresas prestadoras de serviço de colheita de madeira mecanizada apresentam as maiores rentabilidades (49\%), pois as características econômicas dessas empresas (altos custos de capital, depreciações e despesas governamentais) proporcionam essa situação. Tais empresas possuem dirigentes com maior escolaridade, apresentam sistemas de trabalho que permitem uma maior produtividade, podem trabalhar em mais de um turno e não necessitam de grandes estruturas de apoio. 
Tabela 7. Rentabilidade sobre as vendas (EBITDA, de caixa e econômico).

Table 7. Profitability by sales (EBITDA, cash and economic).

\begin{tabular}{lcccc}
\hline Atividade & Grau de mecanização & EBITDA (\%) & Caixa (\%) & Econômico (\%) \\
\hline Silvicultura & Semimecanizado & 39 & 26 & 20 \\
\hline \multirow{3}{*}{ Colheita de madeira } & Manual & 15 & 6 & 4 \\
& Semimecanizado & 11 & 0 & -6 \\
\hline Transporte florestal & Mecanizado & 49 & 32 & 16 \\
\hline
\end{tabular}

A análise pelo método econômico permite afirmar que as empresas de silvicultura, colheita de madeira mecanizada e transporte florestal apresentam rentabilidades superiores a $16 \%$, índice que pode ser considerado bom, visto que as empresas brasileiras de serviços obtiveram índices médios de rentabilidade de, aproximadamente, 19\% no ano de 2007 (GAZETA MERCANTIL, 2008).

As empresas que atuam na colheita de madeira com grau de mecanização semimecanizado apresentam os piores resultados de rentabilidade sobre as vendas - que são até negativos no caso da análise econômica. Esse fato ocorre devido a essas empresas apresentarem um grau de mecanização intermediário, constituído de máquinas e implementos defasados tecnologicamente e com muitos anos de uso e ainda possuírem alto grau de utilização de mão de obra.

\section{Rentabilidade sobre o capital}

As empresas de silvicultura apresentam as melhores situações de rentabilidade sobre o capital em razão do baixo valor imobilizado, pois são pouco mecanizadas e, assim, possuem menores valores investidos em capital, o que proporciona maiores rentabilidades sobre o capital (Tabela 8).

Tabela 8. Rentabilidade sobre o capital (EBITDA, de caixa e econômico).

Table 8 . Profitability by capital (EBITDA, cash and economic).

\begin{tabular}{lcccc}
\hline Atividade & Grau de mecanização & EBITDA (\%) & Caixa (\%) & Econômico (\%) \\
\hline Silvicultura & Semimecanizado & 184 & 121 & 100 \\
\hline \multirow{3}{*}{ Colheita de madeira } & Manual & 168 & 71 & 47 \\
& Semimecanizado & 105 & 51 & 31 \\
& Mecanizado & 67 & 44 & 20 \\
\hline Transporte florestal & Mecanizado & 78 & 59 & 41 \\
\hline
\end{tabular}

Nas empresas de colheita de madeira, a rentabilidade sobre o capital é apropriada, mesmo nas que atuam com sistemas semimecanizados e mecanizados, com índices de 31 e $20 \%$ de rentabilidade econômica, respectivamente, que podem ser considerados satisfatórios quando comparados com os valores nacionais médios para as empresas de serviços, que foram, em 2007, em torno de $21 \%$, segundo a Gazeta Mercantil (2008).

Nas atividades de colheita de madeira mecanizada e transporte florestal, o alto valor do capital existente nessas empresas faz com que a rentabilidade sobre ele seja relativamente menor que nas outras atividades, mas, mesmo assim, esses valores são altos quando comparados com os valores das grandes empresas nacionais.

Apesar de as pequenas empresas terem os menores índices de mecanização e os dirigentes com os menores níveis de escolaridade, elas obtiveram os melhores resultados econômicos quando comparadas com as grandes empresas, fato que ocorre devido à utilização de pouco capital. Por esse motivo, salienta-se que a rentabilidade sobre o patrimônio não é um bom indicador econômico para a análise das micro e pequenas empresas, pois nelas o seu valor é, normalmente, muito baixo.

\section{CONCLUSÕES}

- A composição dos custos das empresas prestadoras de serviço florestal permite concluir que há uma importante participação dos custos indiretos nos custos totais, seja pela elevada necessidade de apoio às atividades de produção, seja devido à alta participação das despesas governamentais nesses custos. 
- Quanto mais alta a participação dos custos fixos em relação aos custos totais das empresas, maior a dependência delas às empresas tomadoras de serviço, pois são estas que definem os volumes de produção e assim controlam a utilização da capacidade instalada das empresas prestadoras de serviço florestal, controlando, por consequência, seus resultados econômicos.

- As atividades de colheita de madeira manual e semimecanizada apresentaram os piores resultados de ponto de equilíbrio. Já as empresas de silvicultura semimecanizada, colheita de madeira mecanizada e transporte florestal apresentaram bons resultados econômicos, principalmente quando se trata da definição do ponto de equilíbrio.

- Nas atividades de colheita de madeira manual e semimecanizada, os resultados obtidos na análise da rentabilidade sobre as vendas foram insuficientes, chegando, em alguns casos, a ser negativos, o que possibilita concluir que as empresas atuam a partir de uma visão de caixa, que decorre do fato de não considerarem nos seus custos os custos de oportunidade de capital e de depreciação, ou de atuarem a partir de uma visão fornecida pelo método EBITDA, que não considera, além dos custos de oportunidade de capital e de depreciação, os custos de impostos.

- A análise apresentada neste estudo foi apropriada para caracterizar economicamente as empresas prestadoras de serviço florestal, pois, de forma estruturada, classificou todos os custos em diretos e indiretos, em fixos e variáveis e em desembolsáveis e não desembolsáveis, para, posteriormente, calcular o lucro a partir da metodologia do EBITDA, de caixa e econômica, além de apresentar o ponto de equilíbrio e a rentabilidade sobre as vendas e sobre o capital das empresas prestadoras de serviço florestal.

\section{REFERÊNCIAS}

ASSOCIAÇÃO BRASILEIRA DE NORMAS TÉCNICAS (ABNT). Avaliação de bens - Parte 5: máquinas, equipamentos, instalações e bens industriais em geral. NBR 14653 - 5. Rio de Janeiro, 2006.

BIRRO, M. H. B.; MACHADO, C. C.; SOUZA, A. P.; MINETTI, L. J. Avaliação técnica e econômica da extração de madeira de eucalipto com "Track-Skidder" em região montanhosa. Revista Árvore, Viçosa, MG: SIF, v. 26, n. 5, p. 525 - 532, 2002.

CAIXA ECONÔMICA FEDERAL (CEF). Poupança. Disponível em: <http://www.caixa.gov.br>. Acesso em: 13/09/2007.

DIAZ, A. L.; MAC DONAGH, P. M. Análisis económico de sistemas de cosecha de Pinus spp. en Misiones, Argentina. Silvoargentina. Mac Donagh y Weber Editores. n. 2, p. 16 - 22, 2001.

DUCATTI, F. A. Formas de definição de preços e reajustes de serviços para as atividades terceirizadas. In: SEMINÁRIO DE ATUALIZAÇÃO SOBRE SISTEMAS DE COLHEITA DE MADEIRA E TRANSPORTE FLORESTAL, 14., 2006. Curitiba. Anais... Curitiba: UFPR: FUPEF, 2006. p. 249 - 261.

GAZETA MERCANTIL. Balanço Anual 2008. São Paulo: Editora JB. 2008.

HILDEBRAND, E. Sistema de apropriação e análise de custos para a empresa florestal. $144 \mathrm{f}$. Dissertação (Mestrado em Engenharia Florestal) - Setor de Ciências Agrárias, Universidade Federal do Paraná, Curitiba, 1995.

HIRSCHFELD, H. Engenharia econômica e análise de custos: aplicações práticas para economistas, engenheiros, analistas de investimentos e administradores. 7. ed. São Paulo: Editora Atlas, 2000. 519 p.

MALINOVSKI, J. R. Metodologia do custo-hora para máquinas florestais. In: CURSO DE ATUALIZAÇÃO SOBRE SISTEMAS DE EXPLORAÇÃO E TRANSPORTE FLORESTAL, 4., 1983, Curitiba. IV Curso de atualização sobre sistemas de exploração e transporte florestal. Curitiba: UFPR/FUPEF, 1983.

MALINOVSKI, R. A. Programa computacional de simulação para análise de sistemas de colheita de madeira. 140 f. Dissertação (Mestrado em Engenharia Florestal) - Setor de Ciências Agrárias, Universidade Federal do Paraná, Curitiba, 1999. 
MALINOVSKI, R. A.; MALINOVSKI, J. R. Evolução dos sistemas de colheita de pinus na região Sul do Brasil. Curitiba: FUPEF, 1998.

MARTINS, E. Contabilidade de custos. 9. ed. São Paulo: Atlas, 2003. 370 p.

MORAIS FILHO, A. D. Análise da capacidade técnica e econômica dos prestadores de serviços no setor de colheita florestal. 103 f. Dissertação. (Mestrado em Recursos Florestais) - Escola Superior de Agricultura “Luiz de Queiroz”, Universidade de São Paulo, Piracicaba, 2006.

PINDYCK, R. S.; RUBINFELD, D. L. Microeconomia. São Paulo: Makron Books, 1994. 968 p.

ROSS, S. A.; WESTERFIELD, H. W.; JASSE, J. F. Administração financeira. São Paulo: Atlas, 1995.

THEISS, J. R.; KRIECK, M. Custos e preços sugeridos de venda: serviços, comércio e indústria; enfoques essencialmente práticos. 2. ed. Blumenau: Odorizzi, 2005. 147 p.

VÄ̈̈TÄINEN, K.; SIKANEN, L.; ASIKAINEN, A. Feasibility of excavator-based harvester in thinnings of peatland forests. International Journal of Forest Engineering, Finland, v. 15, n. 2, 2004.

VALENTE, A. M.; PASSAGLIA, E.; NOVAES, A. G. Gerenciamento de transporte e frotas. São Paulo: Pioneira Thomson Learning, 2003.

VASCONCELOS, Y. L. EBITDA como instrumento de avaliação de empresas. Revista Brasileira de Contabilidade, Brasília, DF, ano XXXI, n. 136, p. 39 - 47, 2002. 
